\title{
Gender as a Moderator of Reciprocal Consumer Behavior
}

Published in the Journal of Consumer Marketing, 2009, 26(3), 200 - 213

\section{Natalia Kolyesnikova}

Department of Nutrition, Hospitality and Retailing Box 41240

Texas Tech University

Lubbock, Texas, USA 79409-1240

Tel: +1 806 742-3077

n.kolyesnikova@ttu.edu

\section{Tim H. Dodd}

Department of Nutrition, Hospitality and Retailing Box 41162

Texas Tech University

Lubbock, Texas, USA 79409-1162

Tel: +1 806 742-3031

tim.dodd@ttu.edu

\section{James F. Wilcox}

Area of Marketing

Rawls College of Business

Box 42101

Texas Tech University

Lubbock, Texas, USA 79409-2101

Tel: +1 806 742-3438

jim.wilcox@ttu.edu 


\title{
Gender as a Moderator of Reciprocal Consumer Behavior
}

\begin{abstract}
Purpose-Purchasing behavior is approached as customer perceived need to reciprocate for services received. The study examines involvement, knowledge, and identity as predictors of reciprocal consumer behavior. Two components of reciprocity - gratitude and obligation - are expected to mediate the relationships. The effect is expected to be different for men and women. Methodology/Approach - Wine was chosen as a product category to test the relationships in the models. Data collection was conducted via distribution of surveys to tasting room visitors at six wineries. The data were analyzed using structural equation modeling.
\end{abstract}

Findings - The impact of knowledge, identity, and involvement were important findings from this research. The differences between males and females with regard to their feelings of gratitude and obligation and the impact on purchasing are pronounced. Obligation to make a purchase had a stronger effect on purchasing behavior of women. In contrast, gratitude (feeling appreciation and thankfulness to personnel) was a stronger reason for men to make a purchase. Practical Implications - Knowledge about different ways in which men and women reciprocate could be useful for researchers and practitioners. Free samples provided to potential buyers, tours of industrial factories where products are also sold, and a variety of service situations are all possible contexts where gratitude and obligation may occur. Purchases are likely to be the result at least in part because of these feelings.

Originality/Value -The major contribution of this research is to highlight the role of gender in reciprocity research and to demonstrate the application of this effect in consumer behavior.

Keywords - gender differences, reciprocity, gratitude, obligation

Paper type - Research paper 


\section{Introduction}

When analyzing consumer differences based on demographic variables, substantial variation has been noted between the behavior of males and females. Men and women behave differently, and consumption is one framework in which these differences often become evident. In spite of the intuitive appeal and everyday occurrence of this conception, the subject of gender differences was underexplored in consumer research until the early 1990's (Costa, 1994). Since then, a substantial number of studies have investigated a variety of perspectives, ranging from processes underlying males' and females' judgment (Dube and Morgan, 1996), to gender strategies relating to information processing (Darley and Smith, 1995), decision making (Mitchell and Walsh, 2004), gift giving (Garbarino and Strahilevitz, 2004; Laroche, Saad, Cleveland, and Browne, 2000), and perceived risk of online shopping (Garbarino and Strahilevitz, 2004).

Gender is a social construct that is intertwined with virtually all aspects of human behavior. Much of the previous research on gendered consumer behavior derived from concepts of societal norms, stereotyping, and culture (Palan, 2001). Less is known about how specifically social norms differ between males and females and how this difference relates to consumption. One of the more interesting gaps is the effect of gender on the norm of reciprocity and the application of this effect in consumer behavior.

\section{Background}

\section{Reciprocity}

The norm of reciprocity traces its roots to Alvin Gouldner (1960), who claimed that for a social system to be stable, there must always be some mutual exchange of benefits, "insofar as men live under such rule of reciprocity, when one party benefits from another, an obligation is 
generated. The recipient is now indebted to the donor, and he remains so until he repays" (p. 174). The norm of reciprocity, therefore, creates motives for returning benefits.

Over the past forty years, numerous studies in social psychology offered empirical support to reciprocity theory. Major findings can be summarized as follows: Receiving even a small favor leads to further compliance with requests of the person who provided the favor (Howard, 1995), even when the favor is unsolicited and unexpected (Regan, 1971), and even when a favor-giver is not perceived as likable (Goei, Massi Lindsey, Boster, Skalski, and Bowman, 2003). Receiving a favor in public conditions creates greater compliance than receiving a favor in private conditions (Whatley, Webster, Smith, and Rhodes, 1999). As the amount of time lengthens between the initial favor and the opportunity to reciprocate, the perceived need to reciprocate diminishes (Burger, Horita, Kinoshita, Roberts, and Vera, 1997).

In the original theory, Gouldner (1960) claimed that the two predictors of reciprocal behavior are gratitude and obligation, "the sentiment of gratitude joins forces with the sentiment of rectitude and adds a safety-margin in the motivation to conformity" (p. 176). Thus, both gratitude and obligation can be antecedents of reciprocal actions. To illustrate, a consumer may feel obligated to purchase skin-care products in return for a free make-over at a cosmetic department due to compliance with social norms resulting from a state of obligation. Yet, the same purchase can be made not so much due to the sense of obligation, but rather out of a desire to show gratitude for enjoyable experiences. For example, the consumer felt appreciation to the make-up consultant. Purchasing then can be a way to express gratitude.

Gratitude has been defined as the positive affective response to receiving a benefit or a favor (Emmons and Crumpler, 2000). Conversely, obligation is a negative, uncomfortable state which is determined by normative demands and can be perceived as aversive (Greenberg and 
Shapiro, 1971). Gratitude was found to lead to further compliance (Emmons and Crumpler, 2000; McCullough, Kilpatrick, Emmons, and Larson, 2001). Similarly, previous research has found that receiving favors increases obligation, and obligation in turn, increases compliance (Greenberg and Frisch, 1972; Greenberg and Saxe, 1975).

Research on the favor-compliance relationship, with the accompanying role of gratitude and obligation, is an important foundation for the present study. We approach purchasing as consumers' perceived need to reciprocate for services received. In its purest sense, quality customer service is not a favor, and purchasing is not compliance. However, some conceptual parallels can be drawn. Obviously, it is reasonable to expect quality customer services. Yet, if customer expectations are met, and especially if the expectations are exceeded, customers may feel appreciative of the staff who provided the services.

In a way, customers experience feelings similar to those that people experience when receiving a favor - that is, appreciation of those who treated them kindly (i.e., gratitude). Following the same reasoning, purchasing is not an equivalent of compliance. However, at least subconsciously, consumers understand that the seller will benefit if they make a purchase. In view of the reciprocity norm, the exchange of benefits should be mutually beneficial. So, on the one hand, consumers may see purchasing as a way to express their gratitude. Alternatively, purchasing may occur because of a perceived need to comply with the reciprocity norm, especially when "the exchange of benefits" takes place in public conditions. In some way, purchasing can be approached as compliance with social norms (i.e., obligation). Thus, there are good reasons to believe that gratitude and obligation may impact consumer purchasing behavior.

As dynamic as the stream of research on reciprocity has been, no previous study was located that has dealt with the possible impact of gender on levels of gratitude and obligation. 
The original theory makes no reference to gender differences, nor does subsequent research on the reciprocity norm. Gender generally has been missing from the research on reciprocity. However, the need for better understanding of gender differences in marketing has been stressed by some leading marketing scholars (Blackwell, Miniard, and Engel, 2001; Kotler and Keller, 2006). The argument presented in this paper is that knowledge about the ways in which men and women reciprocate could be useful for researchers and practitioners.

\section{Gender differences in consumer behavior}

Consumption has long been associated with gender differences, thus, consumer researchers have been examining the impact of gender on consumer behavior. A plethora of studies has focused on biological sex differences (males versus females) in various buying and consuming activities. However, in the early 1960's, consumer researchers (e.g., Aiken, 1963; Vitz and Johnston, 1965) recognized that the subject of gender is more complex, and genderrelated behavior may be based not only on biological differences, but also on gender trait differences. Certain personality traits are associated with masculinity and femininity. For example, masculinity is typically associated with assertiveness, independence, and rationality, while femininity is associated with relational and interdependent aspects such as considerateness, sensitivity, responsibility and caring (Cross and Markus, 1993; Palan, 2001). Thus, the concept of gender identity has been introduced in consumer behavior research.

Gender identity, sometimes referred to as psychological sex, is considered to be a twodimensional phenomenon, where masculine personality traits comprise one dimension, and feminine traits comprise the other (Palan, 2001). An individual may identify him/herself with either set of traits, regardless of his/her biological sex. For example, some men may possess 
personality traits that are mainly associated with femininity, and conversely, some women may possess traits that are more masculine than feminine.

The emergence of new conceptualizations of gender differences has led to a stream of research, which found that gender identity can be a predictor of certain consumer attitudes (e.g., Chang, 2006; Gould and Weil, 1991; Worth, Smith, and Mackie, 1992). However, the value of the gender identity contribution to the understanding of consumer behavior has been questioned. In her comprehensive review of gender consumer research, Palan (2001) states that significant gender identity findings in consumer research have been rare. When comparing the effects of biological sex versus gender identity, in many cases biological sex was found to be far more significant with respect to predicting relationships and attitudes than was gender identity (Allison, Golden, Mullet, and Coogan, 1980; Gould and Weil, 1991; Kahle and Homer, 1985). Biological sex is also a more practical segmentation variable (Palan, 2001).

For these reasons, the current study uses biological sex segmentation to compare reciprocal behavior of males and females. However, despite the criticism, gender identity theory was also used to help provide the conceptual framework for the present study.

Palan (2001) notes that there has been inconsistency in the use of terminology related to gender differences. In recent years, the general convention adopted in literature seems to use the term "sex" to refer to an individual's biological sex (whether one is a man or a woman) and "gender" to refer to the psychological component of an individual. Nevertheless, numerous studies still use the term "gender differences" when comparing behavioral characteristics of males and females (e.g., Bhagat and Williams, 2008; Dittmar, Long, and Meek, 2004; Lyons and Fisher, 2006; Marquis, 2004). The term "gender differences" is used throughout the current 
paper to refer to differences between males and females, regardless of how these differences have been called in previous research.

\section{Gender effect on reciprocity}

A good case of why males and females would respond differently in terms of reciprocity can be built via literature on gender differences in social behavior. In his seminal work on cultural differences, Hofstede (1980) argued that nations differ systematically along four major dimensions, with masculinity (and the opposite pole of femininity) being one of the dimensions. Hofstede found support for the predominant socialization model where men are to be more assertive and for women are to be more nurturing. The analysis of the data on work goals revealed that men almost universally attach more importance to advancement and earnings, while women attach more importance to social goals such as relationships, rendering service, and the physical environment.

For years, research in various disciplines confirmed the male assertiveness-female nurturance pattern. By analyzing ethnographical reports of 110 (mostly non-literate) cultures, Barry, Bacon, and Child (1959) found a universal tendency where girls are socialized toward nurturance, responsibility, and sometimes obedience; while boys are socialized toward achievement and self-reliance. In his book on power, McClelland (1975) examined whether the power drive is expressed differently for men and women. Boys and men were consistently found to be more assertive and more active; girls and women were found to be more sensitive to social interdependence. In another study, participants who scored higher on the masculine characteristics (e.g., aggressive, ambitious, competitive, assertive, self-reliant) of the Sex-Role Inventory scale (Bem, 1974) yielded less to pressure to conform than did those who scored higher on the feminine measure (e.g. affectionate, compassionate, understanding, sensitive to the 
needs of others). An overall tendency for females to conform to a greater extent than their male counterparts was reported by several studies (e.g., Eagly and Chrvala, 1986; Endler, 1966). This is especially true in public situations. Grogan, Bell, and Conner (1997) also found that women's intention to eat sweet snacks was predicted by perceived social pressure and attitudes towards sweet snacks. In addition, men were not found to be influenced by social pressure and were only influenced by attitudes towards sweet snacks.

Early research on gender differences and gender identity has demonstrated that masculinity is typically associated with assertiveness and a cognitive focus on accomplishments. Femininity is associated with nurturance, an emotional concern for the wellbeing of others, and greater conformity to social norms. These findings lead to the expectation that men and women may act differently in response to the norm of reciprocity. Yet, no consumer study was located that investigated gender differences from the reciprocity norm perspective.

In recent years, however, the effect of gender on reciprocity has been investigated extensively in experimental economics. Consistently across numerous experimental settings, women were found to exhibit higher levels of reciprocity than men. Women return a higher percentage of the money they earn to charitable causes than do men (Chaudhuri and Gangadharan, 2003; Croson and Buchan, 1999); women demonstrate an increased responsiveness to another party's behavior (Eckel and Grossman, 1998); and female behavior is more sensitive to context than male behavior (Ben-Ner, Putterman, Kong, and Magan, 2004). On the other hand, males are found to exhibit greater levels of trust (Chaudhuri and Gangadharan, 2003). Men are also less sensitive to the cost of their generous actions when deciding whether or not to be generous (Cox and Deck, 2006). Andreoni \& Vesterlund (2001) suggested that men are more generous than women when the benefit of reciprocity is higher than the cost. 
Overall in the economics literature, women were found to be more reciprocal than men in their (mathematical) ability of interactions. Men were found to be more generous when the stakes are higher. We, however, are more interested in the motivational factors of reciprocal actions of men and women. The review of the literature on gender differences suggests that reciprocal behavior of men would be driven mostly by those forms of reciprocity that are consistent with the overall expectation that men behave assertively. In contrast, reciprocal behavior of women would have more interactive, communal connotations and would encompass mostly caring for other people.

\section{Relevant Consumer Characteristics}

The existing research on reciprocity focuses mainly on the gratitude and obligation effects, with virtually no reference to personality characteristics of respondents. However, it is logical to expect that at least some personality factors could potentially increase or decrease the likelihood of reciprocal actions. In terms of consumer behavior for example, consider product knowledge. A highly knowledgeable consumer may perceive an educational presentation about the product less valuable than a consumer who knows little about the product. Consequently, levels of gratitude to the presenter and/or obligation to reciprocate (e.g., make a purchase) may differ for these two consumers. In the proposed study, product knowledge may become a determinant of consumers' levels of gratitude and/or obligation and possibly, their further reciprocal actions.

There appears a need to look at additional consumer attributes that may potentially influence reciprocal behavior. In the proposed analysis, we examine the effect of product involvement, product knowledge, and identity salience on levels of gratitude and obligation and 
on subsequent reciprocal behavior. The relationships between the constructs are discussed in the proposed model section.

\section{Product involvement}

Consumer product involvement is associated with the perceived importance of a product to consumers (Hupfer and Gardner, 1971). Similarly, Zaichkowsky (1985) defined involvement as a degree of "a person's perceived relevance of an object based on inherent needs, values, and interests" (p. 342).

Previous research analyzed the influences of product involvement on consumer attitudes, brand preferences, and perceptions. Depending on levels of involvement, consumers differ significantly on their purchasing quantities (Lockshin, Spawton, and Macintosh, 1997), perceptions of services (Dodd and Gustafson, 1997), consumption (Goldsmith, d'Hauteville, and Flynn, 1998), as well as satisfaction, store and salesperson trust (Lockshin, Quester, and Spawton, 2001). Since high and low involvement consumers were found to differ in many ways, their levels of gratitude and obligation may be different as well. It also is expected that product involvement may influence consumer reciprocal behavior.

\section{Product knowledge}

Consumer knowledge has been defined as the extent of experiences and familiarity that one has with a product (Alba, 1983; Brucks, 1985). Many researchers (e.g., Flynn and Goldsmith, 1999; Park, Mothersbaugh, and Feick, 1994) follow a three-element classification of knowledge suggested by Brucks (1985): subjective knowledge, objective knowledge, and previous experience with the product. Subjective knowledge is consumer self-perceived level of knowledge. Simply put, subjective knowledge is what consumers think they know about the product. By contrast, objective knowledge is the factual knowledge that is held in a consumer's 
memory and can be measured by a test; that is, objective knowledge is what consumers actually know about the product. Objective and subjective knowledge are generally considered the two components of knowledge, and previous experience a determinant of both (Dodd, Laverie, Wilcox, and Duhan, 2005; Park et al., 1994).

Previous research has found that prior experience with a product was more strongly related to subjective than to objective knowledge (Park et al., 1994). Subjective knowledge was also found a better predictor of purchase decision than was objective knowledge (Raju, Lonial, and Mangold, 1995). In the current research, we expect that consumer perceptions of their knowledge about the product would have a greater impact on consumer reciprocal behavior than would factual, objective knowledge. Thus, subjective self-assessed product knowledge appeared more suitable for this study.

\section{Identity}

In essence, identity refers to a concept of self comprised of the multiple roles we play in society (Stryker, 1968). One's self is a combination of different roles one personalizes. In different situations, people may have different identities. For example, one may have identities as an insurance agent, husband, sport memorabilia collector, cyclist, and wine enthusiast. This approach has been demonstrated to be more meaningful than the historical "global self" approach (Laverie, Kleine, and Kleine Schultz, 2002).

According to the identity salience approach, also known as identity theory (Stryker, 1968), identities are arranged hierarchically, meaning that under certain circumstances, some become more important (i.e., salient) than others. For example, when given a choice, a person who assigns more importance to his/her cyclist identity, would likely be riding a bike alone or with the cycling club or reading the latest issue of "VeloNews." 
In the present study, identity is approached as a behavioral characteristic that may influence individual levels of gratitude and obligation. Identity salience is typically associated with people's participation in a certain activity (e.g., blood donation, aerobic classes, attending sport events). It is expected that a combination of consumer identities and a perceived need to reciprocate may have an impact on consumer purchasing decisions.

\section{Proposed Model and Hypothesized Relationships}

The model depicted in Figure 1 maps the relationships between consumer attributes (involvement, knowledge, and identity) and consumer purchasing. Because purchasing is approached as customer perceived need to reciprocate, we expect that gratitude and obligation would mediate these relationships. We further hypothesize that the effect would be different for men and women.

\section{Place Figure 1 here}

Previous research has explored direct effects of product involvement, product knowledge, and identity salience on consumer purchasing behavior. Research has demonstrated that involvement with a product category is an important determinant of consumer purchasing (Brodowski, 1998; Orth and Firbasova, 2003). Product knowledge also was found to play a significant role in consumer purchasing decisions, especially when there is a perceived risk associated with purchasing (Spawton, 1991). Similarly, Laverie et al. (2002) suggested that identity salience provides insights into why people buy certain goods and services.

The current study extends the defined role of involvement, knowledge, and identity by examining the three variables as predictors of reciprocal behavior. Empirical studies on reciprocity investigated gratitude and obligation as independent predictors of reciprocal actions, 
but not as mediators. Our model posits that involvement, knowledge, and identity can influence purchasing through the mediating variables of gratitude and obligation.

It is expected that depending on levels of product involvement, product knowledge, and identity, consumers would differ in their levels of gratitude and obligation, and consequently, in their purchasing behavior. Highly involved and knowledgeable customers, as well as those who assign importance to their identity associated with a certain activity, are usually more discriminating in their choices. For such customers, certain aspects of their shopping behavior are particularly important, for example having access to an assortment of products or knowledgeable sales personnel. Typically, their expectations of services are high. Unless those expectations are met or exceeded, highly involved and knowledgeable customers are unlikely to feel obligated to buy. If, however, such customers are satisfied with their experiences, they may feel appreciation to those who provided the services. At the same time, it seems that less involved and less knowledgeable customers would feel more obligation to make a purchase in return for services than would highly involved / knowledgeable consumers.

Previous research does not provide adequate reasons to believe that the influence of product involvement, product knowledge, and identity would be different for men and women. Therefore, we hypothesize that the proposed relationship will apply with no effect of gender.

$\mathrm{H}_{1}$ : $\quad$ Product involvement, product knowledge, and identity salience will be related positively to gratitude for males and females.

$\mathrm{H}_{2}$ : Product involvement, product knowledge, and identity salience will be related negatively to obligation for males and females.

For hypotheses 1 and 2, we assumed that the relationship between consumer characteristics and gratitude/obligation will be the same for men and women. Our expectation, 
however, is that the effect of gender will play a role in the next set of the relationships - the impact of gratitude and obligation on purchasing. It is expected that men and women would have different degrees of these feelings which, in turn, would entail different motivations to reciprocate. The nurturing and communal pattern of female social behaviors suggests that when presented with an opportunity to reciprocate, women would be more driven by a desire to help the benefactor. In addition, because previous research found women to be more perceptive of social interdependence, we expect that their reciprocal actions would be based primarily on the sense of obligation to repay the other party. On the contrary, obligation is unlikely to stimulate reciprocal actions of men because the very idea of feeling obligated conflicts with the assertive and independent pattern of males' social behavior. It seems that for men, obligation would be a barrier to preserving independence.

$\mathrm{H}_{3}$ : Obligation will have a stronger effect on purchasing behavior of women than on purchasing behavior of men.

Gratitude, on the other hand, is expected to have a stronger effect on reciprocal actions of men than of women. This is not to say that women will not buy out of a desire to express gratitude, but because women are consistently found to have a sense of responsibility to and for others, it seems that women are more likely to make a purchase even if they do not necessarily feel grateful. Men, on the contrary, do not seem to focus on the sense of obligation to repay others as much as women do. Feeling appreciation and thankfulness (rather than indebtedness) seems to be a stronger reason for men to make a purchase.

$\mathrm{H}_{4}$ : Gratitude will have a stronger effect on purchasing behavior of men than on purchasing behavior of women. 
To summarize, as diagrammed in Figure 1, we assume that consumer product involvement, product knowledge, and identity will influence the level of gratitude and obligation experienced by customers. Gratitude and obligation, in turn, will further impact consumer purchasing. We posit that gender is an indirect factor that will influence purchasing behavior through gratitude and obligation.

\section{Method}

\section{The context of the study}

Wine was chosen as the product category to test the hypotheses for two reasons. First, wine consumers often are known for expressing high product involvement and product knowledge (Dodd et al., 2005; Lockshin et al., 2001). Secondly, the context of visiting a tasting room provides an excellent venue for testing the proposed model - it is a good example of circumstances under which feelings of gratitude and obligation might emerge. During a typical visit to a tasting room, a host (in many cases a winemaker him/herself) offers one or more of the following: a tour, wine tasting, and educational assistance. At the end of their visits, customers may feel thankful for the services provided. Visitors then may feel that buying a bottle of wine is the least they can do to show their appreciation. Alternatively, feelings of obligation (rather than gratitude) may be dominant. For example, it is possible that at least some visitors may feel that leaving the winery without a purchase is simply inappropriate. Or, the sense of obligation may result from a free wine tasting offered at the winery. These feelings of obligation may then trigger purchasing. Thus, the circumstance of visiting a tasting room seemed suitable to test the predictive value of gratitude and obligation, along with other wine consumer characteristics, on visitor reciprocal behavior expressed as purchasing.

\section{Design of the study}


Data collection was conducted via distribution of surveys to tasting room visitors at six US wineries. As visitors were leaving the tasting rooms, the researcher approached them, introduced the study and asked if they were willing to take part in the survey. Those who agreed to participate were provided with a questionnaire, which they completed before leaving the winery. Initially, a total of 371 questionnaires were collected. After eliminating fourteen incomplete questionnaires, 357 cases were left for data analysis.

\section{Measures}

\section{Product involvement}

Product involvement was measured by the modified version (Mittal, 1995) of the Personal Involvement Inventory scale originally developed by Zaichkowsky (1985). Indicators of product involvement were "unimportant /important; means nothing to me/means a lot to me; insignificant/significant; does not matter to me/matters to me," each assessed by a seven-point bipolar scale.

\section{Product knowledge}

The measure of subjective product knowledge was based on the scale developed by Park, Mothersbaugh, \& Feick (1994). Three items, each anchored between very little (1) and very much (7), measured participant self-reported assessment of product knowledge: "How much do you feel you know about wine?"; "Compared to your friends and acquaintances, how much do you feel you know about wine?" and "Compared to a wine expert, how much do you feel you know about wine?"

\section{Identity Salience}

The wine tourist identity salience measurement was adapted from Callero's (1985) scale originally developed to measure a blood donor identity. The scale was adapted to reflect the 
context of the present study: "Visiting a winery is something I rarely think about" (reverse coded); "For me, visiting a winery means more than just drinking wine"; "Visiting wineries is an important part of who I am"; and "I really don't have any clear feelings about visiting wineries" (reverse-coded). Each item was measured on a seven-point scale with strongly disagree (1) and strongly agree (7) as anchors.

\section{Gratitude and Obligation}

To our knowledge, previous research on gratitude and obligation has been conducted using experimental methods. Feelings of gratitude and obligation were evoked though manipulation of a favor (e.g., a stranger (confederate) unexpectedly brings a soft drink (Regan, 1971)). It is not until recently that social psychologists (Goei and Boster, 2005) first attempted to implement a pen-and-paper measurement for gratitude and obligation. We based the development of our scale on their findings. However, the current study was not subject to experimental control. It did not seem realistic to experimentally induce feelings of gratitude and/or obligation in a winery setting. The majority of Goei and Boster's scale items could not be directly applied to our study. Therefore, a multi-item scale was developed to measure the degree of gratitude and obligation experienced by winery visitors.

Following Churchill's (2004) recommendations for scale development, both pre-testing and a pilot study were employed. The first pretest was administered to 59 undergraduate students at a large public university in the United States. The purpose of the pre-testing was to generate a comprehensive list of items. Two sets of simulated scenarios were developed to create situations similar to visiting a winery. One scenario featured a visit to a brewery with beer tasting and a tour; the other described a visit to a department store where a make-up consultant offered a free make-over. The scenarios ended with open-ended questions. The participants were asked to 
describe feelings that they would experience at these events. An initial list of items that could potentially be antecedents to purchasing driven by feelings of gratitude or obligation was developed through the content analysis of the respondents.

The researchers then employed a second pre-testing to ensure the power of the items. Twelve people, who traveled to wineries in the past, were recruited to participate in a focus group. Participants were asked about factors that influenced their decisions to buy or not to buy wine and/or souvenirs at wineries. Given that purchasing driven by gratitude or obligation may be of a subconscious nature, questions about feelings of appreciation to winery personnel, obligation, normative pressure, and other factors were asked both indirectly and directly. Next, a pilot study was conducted to ensure the reliability of the instrument.

For the pilot study, the instrument was administered to winery visitors. The data were analyzed to ensure the reliability of the instrument. The final list of items to measure gratitude and obligation included the instruction question, "To what extent did the following factors affect your decision whether to purchase wine?" and was followed by a list of factors, (1) "desire to say "thank you" to the winery personnel"; (2) "buying wine was the socially proper thing to do"; (3) "feelings of ethical indebtedness to buy wine", (4) "purchase expectation from winery personnel", (5) "in return for wine tasting", and (6) "in return for the tour." The items were measured on a Likert-type scale, anchored between least likely (1) and most likely (7).

\section{Amount Spent}

Purchasing was measured using a two-item scale. Respondents reported a dollar amount spent on wine and on items other than wine (accessories). Actual receipts were used by those respondents who made a purchase. Respondents who did not buy wine and/or souvenirs entered 
"zero" (\$0.00). For data analysis, the total spending (i.e., a combined amount spent on wine and accessories) was used as a measure of purchasing.

\section{Preliminary Data Analysis}

\section{Data Reduction}

To determine the underlying structures of the newly developed gratitude and obligation scale, the measure was initially subjected to principal axis factoring with varimax rotation. An examination of factor loadings, eigenvalues greater than one, and the scree plot suggested two factors. The first factor was defined by three loading values that were related to positive affective responses to receiving services at a winery, namely (a) desire to say "thank you" to winery personnel, (b) appreciation of the wine tasting, and (c) appreciation of the tour. We labeled this factor gratitude. The second factor was composed of three items that had more obligatory meaning, namely (a) ethical indebtedness to buy wine, (b) purchase expectation from winery personnel, and (c) normative pressure ("I feel that buying wine is a socially proper thing to do"). We labeled this factor obligation. The two factors accounted for $55.67 \%$ of the total variance. Correlation analyses revealed that the items on each factor showed a high degree of internal consistency indicating that the three items on each factor were measuring a single, similar construct. Cronbach's alpha $(\alpha)$ for the gratitude factor was .87 ; for the obligation factor $\alpha=.73$. The results of the factor analysis were consistent with previous research on dimensionality of the gratitude and obligation constructs (Goei and Boster, 2005) and confirmed that gratitude and obligation are two distinct constructs and can be operationally differentiated.

Measures of product involvement, product knowledge, and identity were composed of items from several scales purporting to measure these constructs (Callero, 1985; Mittal, 1995; Park et al., 1994). However, since these measures had been developed and tested elsewhere, they 
were examined (along with the measures of gratitude and obligation) in a confirmatory factor analysis. The initial fit of the items (17 in all) was not very $\operatorname{good}\left(\chi^{2}=354.32, \mathrm{df}=109\right.$, RMSEA $=.08, \mathrm{RMR}=.07, \mathrm{GFI}=.89, \mathrm{NNFI}=.96$, and $\mathrm{CFI}=.97)$. Thee items (one each from identity, product knowledge and involvement ) exhibited significant cross-loadings and were deleted, resulting in a final measurement model of 14 items which had a better than moderate fit $\left(\left(\chi^{2}=\right.\right.$ $153.04, \mathrm{df}=65, \mathrm{RMSEA}=.061, \mathrm{RMR}=.06, \mathrm{GFI}=.94, \mathrm{NNFI}=.98$, and CFI $=.98)$. The items, their loadings and construct reliability are reported in Table 1 . These measures were deemed acceptable to test the hypothesized relationships in a structural model.

Place Table 1 here

\section{Results}

\section{Description of the sample}

The sample consisted of slightly more women $(n=191)$ than men $(n=166)$. The average age of respondents was 41 years and seventy-three percent were under 51 years of age. Respondents had high levels of education with two-thirds of the sample having earned either an undergraduate or graduate degree. Only 5.6\% had not attended college. Almost one-third reported that their annual household incomes exceed $\$ 100,000$. Overall, the socio-demographic background of visitors to the sampled wineries (middle-aged, educated, with higher incomes) mirrored the profile of wine consumers in general (Motto Kryla \& Fisher, 2000).

\section{Hypotheses testing}

First, we tested whether men and women spent different amounts of money at the wineries. No significant differences in expenditures were found. Amounts spent by men $(M=$ $29.86, S D=34.47)$ were not different from amounts spent by women $(M=30.68, S D=34.41)$, 
$t(355)=.224, p=.823$. Therefore, even though the expenditures for males and females were found to be similar, the reasons for spending money could be different.

Further analysis of data was conducted in two stages. First, separate models with the structural relationships depicted in Figure 1 were estimated for the male and female portions of the sample. Because Gratitude and Obligation were expected to be correlated yet were not related to one another in the model, a second-order construct was included to account for the correlation. The second-order construct does not relate to anything in the model except Gratitude and Obligation. The results are reported in Tables 2 and 3 for females and males, respectively. Both models suggest a reasonable fit to the data (Females: $\chi^{2}=159, d f=78$, RMSEA $=.068$, $\mathrm{GFI}=.90, \mathrm{NNFI}=.98$, and CFI $=.95$; Males: $\chi^{2}=162, d f=78, \mathrm{RMSEA}=.074, \mathrm{GFI}=.89$, $\mathrm{NNFI}=.98$, and CFI $=.97)$ although the model appears slightly better able to account for the relationships in the female sample. Further, the female sample was able to account for $31 \%$ of the variance in Amount Spent while for the males; $R^{2}$ for Amount Spent only reached 21\%.

Place Tables 2 and 3 here

The hypotheses implied by Figure 1 (each path is a hypothesis involving a relationship and no path, hypothesizes the lack of a relationship) were not all supported by the results. However, before interpreting these results, it is necessary to answer the more basic question: do men and women differ in the direction and/or magnitude of relationships among the constructs? To address this question, two-group structural equation modeling was used. It required two runs. In the first, the parameters in each group are estimated separately although the same sets of parameters are estimated in each. This results in a $\chi^{2}$ value for goodness of fit. In the second run, the structural parameters (the ones representing the relationships) are constrained to be equal 
across models and a $\chi^{2}$ value is again generated. In both tests, the parameters relating to measurement, variances and error terms are free to be estimated separately. Thus, the difference in $\chi^{2}$ (with the appropriate difference in degrees of freedom) is a test of the equivalence of the structural portion of the two models. For this study, the fit resulting from estimating the unconstrained models was $\chi^{2}=333$ with degrees of freedom $=165$. The fit for the constrained models was $\chi^{2}=356$ with degrees of freedom $=156$. The difference is $\chi^{2}=23$ with 9 degrees of freedom, suggesting the two models are different with a p-value of $<.01$.

Place Figures 2 and 3 here

\section{Discussion}

Gender differences, the impact of knowledge, identity and the role of involvement were all important findings from this research. The differences between males and females with regard to their feelings of obligation and gratitude and the impact on purchasing are pronounced. The role that knowledge plays is also important and seems similar to that found by Nayga (2000) who noted that gender effect was especially notable because of differences in knowledge level with respect to nutrition knowledge and behavior.

$\mathrm{H}_{1}$ hypothesized that product involvement, product knowledge, and identity salience will be related positively to gratitude for both men and women. $\mathrm{H}_{1}$ was not supported. No relationship between identity, product knowledge, product involvement, and gratitude were found that would apply identically for both men and women. In fact, the relationships were quite different for males and females except for product involvement where, for both genders, there was no path to gratitude, but a strong direct relationship to amount spent. The only positive relationship was for men between product knowledge and gratitude. Contrary to predictions, the 
path from their identity of wine tourists to gratitude was found to be negative. For both identity and product knowledge the relationship for women was not significant.

$\mathrm{H}_{2}$ predicted that product involvement, product knowledge, and identity salience would be related negatively to obligation. $\mathrm{H}_{2}$ was partially supported and differences were again found between men and women. As hypothesized, identity was negatively related to obligation for both men and women indicating that higher identity as wine tourists leads to lower feelings of obligation to make a purchase. Product involvement also performed as expected with negative relationships to obligation for both men and women. For product knowledge, the relationship was the opposite as predicted for males and not significant for females.

$\mathrm{H}_{3}$ hypothesized that obligation will have a stronger effect on purchasing behavior of women than on purchasing behavior of men. In a similar way, $\mathrm{H}_{4}$ hypothesized that gratitude will have a stronger effect on the purchasing behavior of men than on the purchasing behavior of women. Both $\mathrm{H}_{3}$ and $\mathrm{H}_{4}$ were supported with women having a strong positive relationship between obligation and purchasing and no relationship between gratitude and purchasing. For men, gratitude was related to purchasing while obligation was not.

The results add weight to the notion that gender differences influence how identity and product knowledge impact feelings of gratitude and obligation and how these constructs impact purchasing. No gender differences were noted for product involvement. Reasons for this difference between the genders cannot be determined from this research but it seems that men typically are at least in part influenced in their purchases by gratitude while women tend to be influenced by obligation.

For males, product knowledge positively impacts gratitude and identity negatively impacts gratitude. In turn, gratitude seems to positively impact amount spent. Males visiting 
wineries with existing high levels of knowledge are likely to want to spend money only if they find something special and can feel like they appreciated the experience with respect to the tour and a desire to say "thank you". This is consistent with the literature with regard to both the knowledge construct and the impact of gratitude on purchasing. The assertive responses to male's experience in terms of positive feelings tend to drive purchases rather than stimulate more submissive feelings of obligation. This also may be driven by male's feelings of self confidence and reliance as the level of knowledge increases. Males simply want to act in a practical manner associated with gratitude for the experience they enjoyed, while for women social and emotional aspects are what will drive purchases. Grogan, Bell, and Conner (1997), for instance, noted that intentions by women to eat sweet snacks were predicted by social pressure. For males this was not the case. The researchers concluded that men are influenced less by social pressure concerning sweet snacking. Thus, female behavior (purchasing in this case) seems to be influenced by the social aspects related to obligation. This is especially true in public situations. Males, on the other hand, make purchases based on activity and their individual choices, but this behavior would tend to be assertive and so purchasing would come from this more action oriented construct of gratitude.

Reasons for the negative relationship between identity and gratitude are unclear but it is possible that males with higher levels of identity salience towards being a wine tourist take a more critical view of the experience and because they have more emotional attachment to the tour are less willing to show gratitude. The differences between identity and knowledge indicate that males may have substantial knowledge about wine but do not necessarily feel like the activity of touring a winery is an important part of who they are as wine consumers. Identity and product involvement however seem to perform in a similar way (although no path was found to 
gratitude from product involvement). Both identity and involvement showed negative paths to obligation and identity had a negative path to gratitude, indicating the close relationship between the importance of a product to an individual (product involvement) and the feeling of self and how we identify with a particular product or activity (identity).

Whether women are involved and knowledgeable about wine, or identify with winery tours, does not seem to influence their feelings of gratitude. Instead, obligation is the focus for the manner in which spending seems to occur with women. The path to spending from obligation is positive while for gratitude it is not significant. The literature predicted this relationship as females, partly because of societal norms, tend to act out of feelings of obligation. These feelings in a winery could be the result of other people in the room making purchases or just a feeling of the need to buy something because 'it is the right thing to do'. Even if they don't purchase wine, females may decide to purchase an accessory item as a way to sooth their conscience for kindness shown during their visit. The positive relationship from product knowledge and the negative relationships of identity and product involvement are the predictors in this model of these obligatory feelings. For the knowledge construct this relationship is the mirror image of the model for men's reciprocal behavior. Females with greater levels of knowledge appear to have increased levels of feelings of obligation in this setting. This may be because as females learn more about wine they begin to feel more responsible for acting in a certain manner. The subsequent purchasing behavior is one of these norms that females relate to that obligation from their knowledge of wine.

The strong direct path from product involvement to purchasing has been noted in a variety of studies of wine and other products (Dodd and Gustafson, 1997; Lockshin et al., 1997; Quester and Smart, 1998). This direct positive path is the same for both men and women and 
highlights that as people place more importance on a product category they will typically spend more on that product and associated items.

\section{Conclusions and Managerial Implications}

The major contribution of this research is to highlight the role of gender in reciprocity research. The current study provides service managers with new insights to developing better marketing strategies. Managers need to be aware that in addition to objective product characteristics, customers purchasing decisions may be driven by less obvious factors, such as those investigated in this study - feelings of gratitude and obligation. This understanding will lead to a more critical look at marketing strategies aimed at establishing relationships with a customer.

Findings of the current study demonstrate that males and females tend to reciprocate for different reasons and this may have significance in a number of consumer situations. Free samples provided to potential buyers, tours of industrial factories where products are also sold, and a variety of service situations are all possible situations where gratitude and obligation may be present. Purchases are likely to be the result at least in part because of these feelings.

The main limitation of this research is that it was limited to just one setting (winery visits) and the complex experience of tours, wine tastings, and being with other people in a social session, may be difficult to be replicated in other consumer situations. Additional research to examine the role that obligation and gratitude play in various settings would be helpful for better understanding the role that gender plays and how it interacts with other constructs. This is a potentially new line of research and a range of other types of studies in various settings will be needed to further examine the various links between gender and reciprocity in consumer situations. 
Figure 1. Proposed Model of Gender Differences in Consumer Reciprocal Behavior

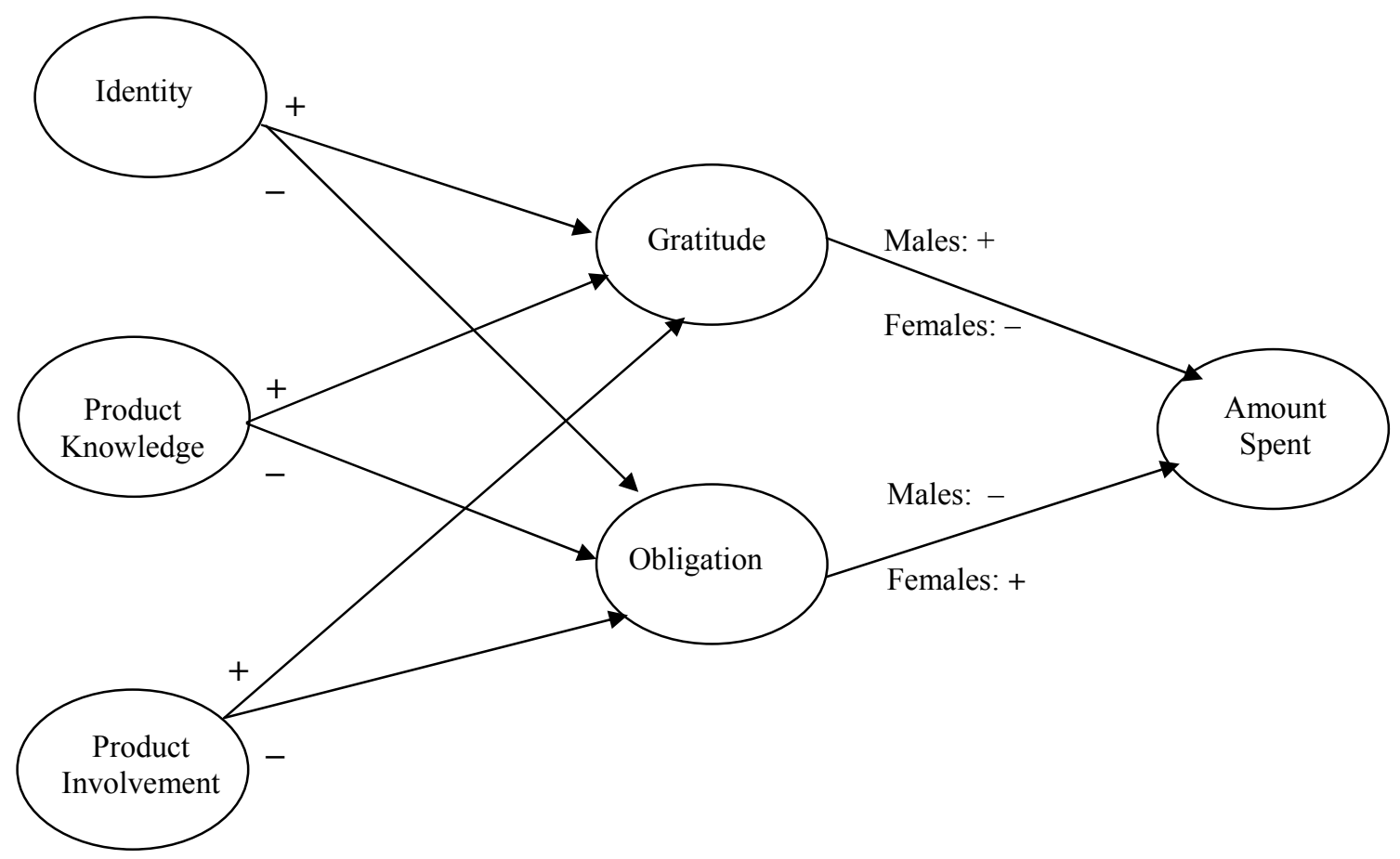


Figure 2. Model for Women's Consumer Reciprocal Behavior

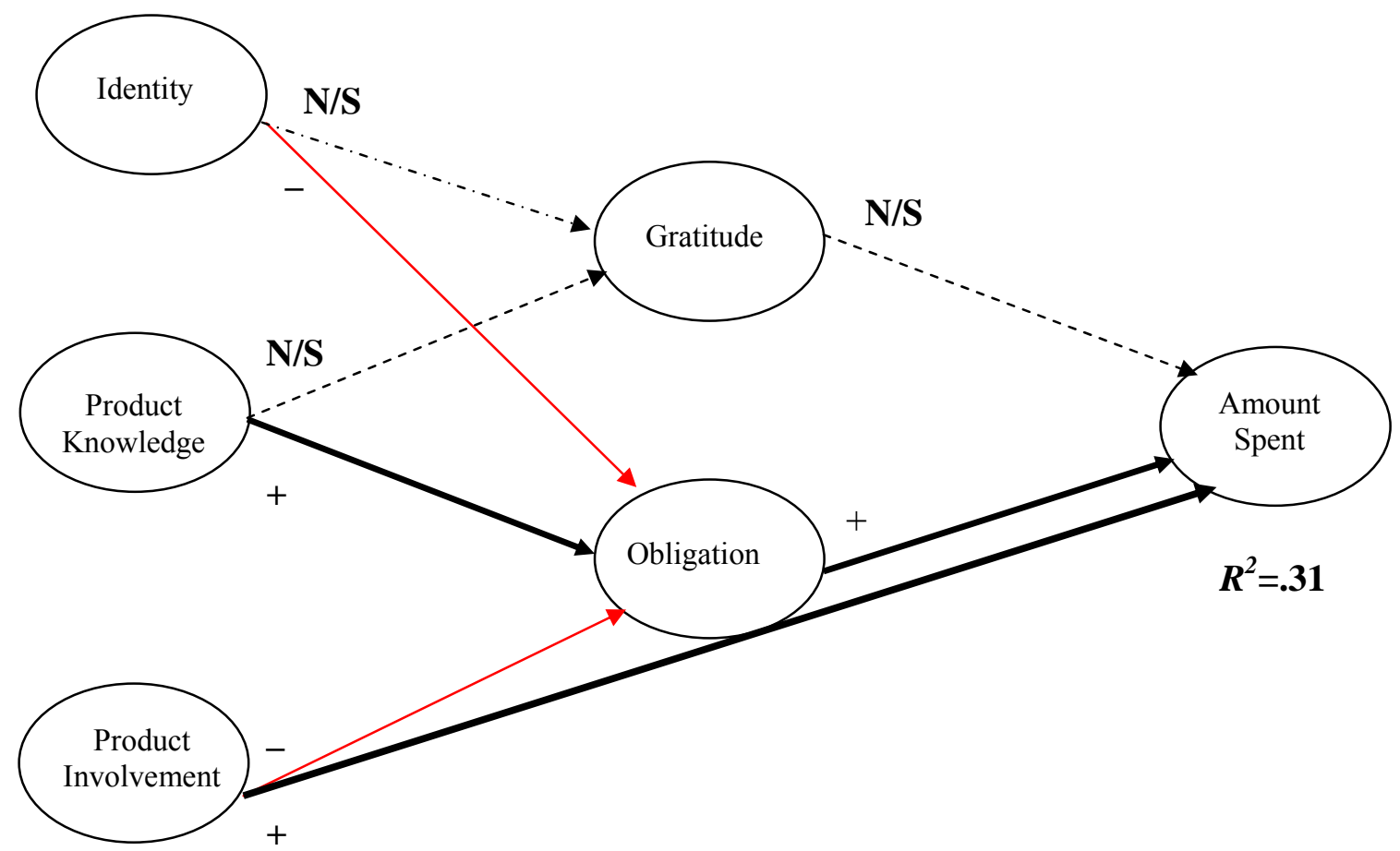

Fit

Chi-Square $=159(d f 78)$

RMSEA $=.068$

$\mathrm{GFI}=.90$

$\mathrm{NNFI}=.95$ 
Figure 3. Model for Men's Consumer Reciprocal Behavior

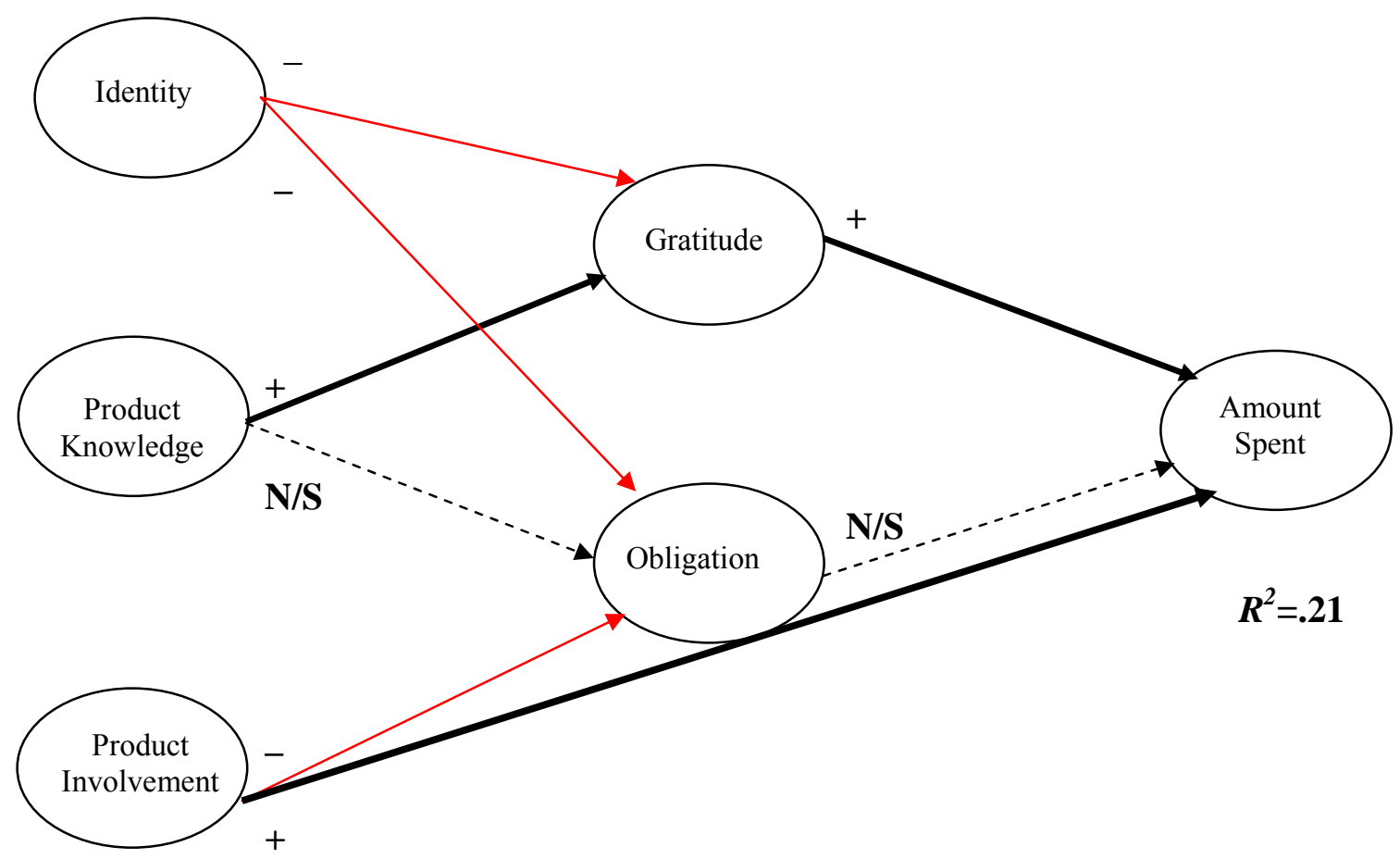

Fit

Chi-Square $=162(d f 78)$

RMSEA $=.074$

$\mathrm{GFI}=.89$

$\mathrm{NNFI}=.95$ 
Table 1. Items and Psychometric Properties of the Five Constructs

Construct

$\underline{\text { Loading Reliability }}$

Gratitude (Did not (1) to strongly (7) affected decision to buy wine)

Desire to say 'thank you' to the winery personnel $\quad .88$

Wanted to buy wine in return for wine tasting $\quad .86$

Wanted to buy wine in return for the tour $\quad .82$

Obligation (Did not (1) to strongly (7) affected decision to buy wine)

Felt it was a socially proper thing to do. $\quad .74$

Felt an ethical indebtedness. $\quad .54$

Felt a purchase expectation from winery personnel. $\quad .66$

Identity (Strongly Disagree (1) to Strongly Agree (7))

Visiting a winery is something I rarely think about.

For me, visiting a winery means more than just drinking wine. $\quad .54$

I really don't have any clear feelings about visiting wineries. $\quad .75$

Product Knowledge (Very Little (1) to Very Much (7))

How much do you feel you know about wine? $\quad .96$

Compared to your friends and acquaintances,

how much do you feel you know about wine?

Product Involvement

Wine to me:

Means nothing (1) to Means a lot (7)

Insignificant (1) to Significant (7)

Does not matter (1) to Matters(7) 
Table 2. Parameter Estimates for Hypothesized Relationships: Female Sample ${ }^{\text {a }}$

\section{Path Relationships}

\section{Direct Relationships}

From

Gratitude

Obligation

Product Involvement

Product Involvement

Product Knowledge

Product Knowledge

Identity

Identity

Indirect Relationships

Identity

Knowledge

Product Involvement -

Amount Spent

Amount Spent

Amount Spent

Obligation

Obligation

Gratitude

Obligation

Gratitude

Amount Spent

Amount Spent

Amount Spent
Parameter

Estimate $^{\mathrm{b}}$

.09

.43

.39

$-.46$

.51

.05

$-.43$

$-.24$

$-.21$

.22

$-.20$
As

t-value $^{\mathrm{c}}$ Expected? $^{\mathrm{d}}$

ns

no

$3.1 \quad$ yes

5.3 yes

-3.4 yes

3.0 no

ns no

$-2.9 \quad$ yes

ns no

${ }^{\mathrm{a}}$ Fit: $\chi^{2}=159, d f=74 ; \mathrm{RMSEA}=.068 ; \mathrm{GFI}=.90 ; \mathrm{NNFI}=.95 ;$ and $\mathrm{CFI}=.96$

${ }^{\mathbf{b}}$ Standardized Coefficients

${ }^{\mathrm{c}}$ All t-values greater than 1.64 are significant at $(\mathrm{p}<.05)$, one-tailed test.

${ }^{\mathrm{d}}$ From relationships depicted in Figure 1. 
Table 3. Parameter Estimates for Hypothesized Relationships: Male Sample ${ }^{\text {a }}$

\section{Path Relationships}

\section{Direct Relationships}

From

Gratitude

Obligation

Product Involvement

Product Involvement

Product Knowledge

Product Knowledge

Identity

Identity

Indirect Relationships

Identity

Knowledge

Product Involvement - -

Amount Spent

Amount Spent

Amount Spent

Obligation

Obligation

Gratitude

Obligation

Gratitude

Amount Spent

Amount Spent

Amount Spent
Parameter

Estimate $^{\text {b }}$

.34

.07

.38

$-.32$

.08

.33

$-.57$

$-.63$

$-.25$

$-3.1$

.12

$-.02$
As

t-value $^{\text {c }}$ Expected? $^{\mathrm{d}}$

2.2 yes

ns no

$3.0 \quad$ yes

-2.6 yes

ns no

$2.3 \quad$ yes

$-3.8 \quad$ yes

-3.5 no

${ }^{\mathrm{a}}$ Fit: $\chi^{2}=162, d f=78 ; \mathrm{RMSEA}=.074 ; \mathrm{GFI}=.89 ; \mathrm{NNFI}=.96$; and $\mathrm{CFI}=.97$

${ }^{\mathbf{b}}$ Standardized Coefficients

${ }^{\mathrm{c}}$ All $\mathrm{t}$-values greater than 1.64 are significant at $(\mathrm{p}<.05)$, one-tailed test.

${ }^{\mathrm{d}}$ From relationships depicted in Figure 1. 


\section{References}

Aiken, L. R. (1963), "The relationship of dress to selected measures of personality in undergraduate women", Journal of Social Psychology, Vol. 59, No. 1, pp. 119-128.

Alba, J. W. (1983), "The effects of product knowledge on the comprehension, retention, and evaluation of product information", Advances in Consumer Research, Vol. 10, pp. 577580 .

Allison, N. K., Golden, L. L., Mullet, G. M. and Coogan, D. (1980), "Sex-typed product images: The effects of sex, sex role self-concept and measurement implications", Advances in Consumer Research, Vol. 7, pp. 604-609.

Andreoni, J. and Vesterlund, L. (2001), "Which is the fair sex? Gender differences in altruism", Quarterly Journal of Economics, Vol. 116, No. 1, pp. 293-312.

Barry, H. I., Bacon, M. K. and Child, I. L. (1959), "A cross-cultural survey of some sex differences in socialization", Journal of Abnormal and Social Psychology, Vol. 55, pp. 327-332.

Bem, S. L. (1974), "The measurement of psychological androgyny", Journal of Consulting and Clinical Psychology, Vol. 42, No. 2, pp. 155-162.

Ben-Ner, A., Putterman, L., Kong, F. and Magan, D. (2004), "Reciprocity in a two-part dictator game", Journal of Economic Behavior and Organization, Vol. 53, pp. 333-353.

Bhagat, P. S. and Williams, J. D. (2008), "Understanding gender differences in professional service relationships", Journal of Consumer Marketing, Vol. 25, No. 1, pp. 16-22.

Blackwell, R. D., Miniard, P. W. and Engel, J. F. (2001), Consumer behavior, (9th ed.). Harcourt College Publishers, Fort Worth, TX.

Brodowski, G. H. (1998), "The effects of country-of-design and country-of-assembly on evaluative beliefs about automobiles and attitudes toward buying items: A comparison between low and high ethnocentric consumers", Journal of International Consumer Marketing, Vol. 10, No. 3, pp. 85-113.

Brucks, M. (1985), "The effects of product class knowledge on information search behavior", Journal of Consumer Research, Vol. 12, No. 1, pp. 1-16.

Burger, J. M., Horita, M., Kinoshita, L., Roberts, K. and Vera, C. (1997), "Effects of time on the norm of reciprocity", Basic and Applied Social Psychology, Vol. 19, No. 1, pp. 91-100.

Callero, P. L. (1985), "Role-identity salience", Social Psychology Quarterly, Vol. 48, No. 3, pp. 203-215.

Chang, C. (2006), "The influence of masculinity and femininity in different advertising processing contexts: An accessibility perspective", Sex Roles, Vol. 55, No. 5, pp. 345356.

Chaudhuri, A. and Gangadharan, L. (2003), Gender differences in trust and reciprocity, (No. 248). Auckland, New Zealand: University of Auckland.

Churchill, G. A. (2004), Basic marketing research, (5th ed.). South-Western, Mason: OH.

Costa, J. A. (1994), Gender issues and consumer behavior. Sage Publications, Thousand Oaks, CA.

Cox, J. C. and Deck, C. A. (2006), "When are women more generous than men?" Economic Inquiry, Vol. 44, No. 4, pp. 587-598.

Croson, R. and Buchan, N. (1999), "Gender and culture: International experimental evidence from trust games", American Economic Review, Vol. 89, No. 2, pp. 386-391. 
Cross, S. E. and Markus, H. R. (1993), "Gender in thought, belief, and action: A cognitive approach", in A. E. Beall \& R. J. Sternberg (Eds.), The Psychology of Gender (pp. 5598). New York, NY, Guilford Press.

Darley, W. K. and Smith, R. E. (1995), "Gender differences in information processing strategies: An empirical test of the selectivity model in advertising response", Journal of Advertising, Vol. 24, No. 1, pp. 41-56.

Dittmar, H., Long, K. and Meek, R. (2004), "Buying on the Internet: Gender differences in online and conventional buying motivations", Sex Roles, Vol. 50, No. 5, pp. 423-444.

Dodd, T. H. and Gustafson, A. W. (1997), "Product, environment, and service attributes that influence consumer attitudes and purchases at wineries", Journal of Food Products Marketing, Vol. 4, No. 3, pp. 41-59.

Dodd, T. H., Laverie, D. A., Wilcox, J. F. and Duhan, D. F. (2005), "Differential effects of experience, subjective knowledge and objective knowledge on sources of information used in consumer wine purchasing", Journal of Hospitality and Tourism Research, Vol. 29, No. 1, pp. 3-19.

Dube, L. and Morgan, M. S. (1996), "Trend effects and gender differences in retrospective judgments of consumption emotions", Journal of Consumer Research, Vol. 23, No. 2, pp. $156-162$.

Eagly, A. H. and Chrvala, C. (1986), "Sex differences in conformity: Status and gender role interpretations", Psychology of Women Quarterly, Vol. 10, No. 3, pp. 203-220.

Eckel, C. C. and Grossman, P. J. (1998), "Are women less selfish than men? Evidence from dictator experiments", The Economic Journal, Vol. 108, No. 448, pp. 726-735.

Emmons, R. A. and Crumpler, C. A. (2000), "Gratitude as a human strength: Appraising the evidence", Journal of Social and Clinical Psychology, Vol. 19, pp. 56-69.

Endler, N. S. (1966), "Conformity as a function of different reinforcement schedules", Journal of Personal and Social Psychology, Vol. 3, pp. 175-180.

Flynn, L. R. and Goldsmith, R. E. (1999), "A short, reliable measure of subjective knowledge", Journal of Business Research, Vol. 46, No. 1, pp. 57-66.

Garbarino, E. and Strahilevitz, M. (2004), "Gender differences in the perceived risk of buying online and the effects of receiving a site recommendation", Journal of Business Research, Vol. 57, pp. 768-775.

Goei, R. and Boster, F. J. (2005), "The roles of obligation and gratitude in explaining the effect of favors on compliance", Communication Monographs, Vol. 72, pp. 284-300.

Goei, R., Massi Lindsey, L. L., Boster, F. J., Skalski, P. D. and Bowman, J. M. (2003), "The mediating roles of liking and obligation on the relationship between favor and compliance", Communication Research, Vol. 30, pp. 178-197.

Goldsmith, R. E., d'Hauteville, F. and Flynn, L. R. (1998), "Theory and measurement of consumer innovativeness: A transnational evaluation", European Journal of Marketing, Vol. 32, No. 3/4, pp. 340-353.

Gould, S. J. and Weil, C. E. (1991), "Gift-giving roles and gender self-concepts", Sex Roles, Vol. 24, No. 9, pp. 617-637.

Gouldner, A. W. (1960), "The norm of reciprocity: A preliminary statement", American Sociological Review, Vol. 25, No. 2, pp. 161-178.

Greenberg, M. S. and Frisch, D. M. (1972), "Effect of intentionality on willingness to reciprocate favor", Journal of Experimental Social Psychology, Vol. 8, pp. 99-111. 
Greenberg, M. S. and Saxe, L. (1975), "Importance of locus of help initiation and type of outcome as determinants of reactions to another's help attempt", Social Behavior and Personality, Vol. 3, pp. 101-110.

Greenberg, M. S. and Shapiro, S. P. (1971), "Indebtedness: An adverse aspect of asking for and receiving help", Sociometry, Vol. 34, pp. 290-301.

Grogan, S. C., Bell, R. and Conner, M. (1997), "Eating sweet snacks: Gender differences in attitudes and behaviour", Appetite, Vol. 28, No. 1, pp. 19-31.

Hofstede, G. H. (1980), Culture's consequences: International differences in work-related values. Sage Publications, Beverly Hills, CA.

Howard, D. J. (1995), "Chaining the use of influence strategies for producing compliance behavior", Journal of Social Behavior and Personality, Vol. 10, No. 1, pp. 169-185.

Hupfer, N. T. and Gardner, D. M. (1971), Differential involvement with products and issues: An exploratory study, Paper presented at the Second Annual Conference of the Association for Consumer Research, College Park, MD.

Kahle, L. R. and Homer, P. (1985), "Androgyny and midday mastication: Do real men eat quiche?" Advances in Consumer Research, Vol. 12, pp. 242-246.

Kotler, P. and Keller, K. L. (2006), Marketing management, (12th ed.). Pearson Prentice Hall, Upper Saddle River, NJ.

Laroche, M., Saad, G., Cleveland, M. and Browne, E. (2000), "Gender differences in information search strategies for a Christmas gift", Journal of Consumer Marketing, Vol. 17, No. 6, pp. 500-522.

Laverie, D. A., Kleine, R. E. and Kleine Schultz, S. (2002), "Re-inquiries - reexamination and extension of Kleine, Kleine, and Kernan's social identity model of mundane consumption: The mediating role of the appraisal process", Journal of Consumer Research, Vol. 28, No. 4, pp. 659-669.

Lockshin, L., Quester, P. G. and Spawton, A. L. (2001), "Segmentation by involvement or nationality for global retailing: A cross-national comparative study of wine shopping behaviours", Journal of Wine Research, Vol. 12, No. 3, pp. 223-236.

Lockshin, L., Spawton, A. L. and Macintosh, G. (1997), "Using product, brand, and purchasing involvement for retail segmentation", Journal of Retailing and Consumer Services, Vol. 4, No. 3, pp. 171-183.

Lyons, A. C. and Fisher, J. (2006), "Gender differences in debt repayment problems after divorce", Journal of Consumer Affairs, Vol. 40, No. 2, pp. 324-346.

Marquis, M. (2004), "Strategies for influencing parental decisions on food purchasing", Journal of Consumer Marketing, Vol. 21, No. 2, pp. 134-143.

McClelland, D. C. (1975), Power: The inner experience. Irvington, New York, NY.

McCullough, M., Kilpatrick, S. D., Emmons, R. A. and Larson, D. B. (2001), "Is gratitude a moral affect?" Psychological Bulletin, Vol. 127, pp. 249-266.

Mitchell, V.-W. and Walsh, G. (2004), "Gender differences in German consumer decisionmaking styles", Journal of Consumer Behaviour, Vol. 3, No. 4, pp. 331-346.

Mittal, B. (1995), "A comparative analysis of four scales of consumer involvement", Psychology and Marketing, Vol. 12, No. 7, pp. 663-682.

Motto Kryla \& Fisher, L. (2000), U.S. wine demographics report. St. Helena, CA: The Wine Business Center.

Nayga, R. M. (2000), "Nutrition knowledge, gender, and food label use", Journal of Consumer Affairs, Vol. 34, No. 1, pp. 97-112. 
Orth, U. R. and Firbasova, Z. (2003), "The role of consumer ethnocentrism in food product evaluation", Agribusiness, Vol. 19, No. 2, pp. 137-153.

Palan, K. M. (2001), "Gender identity in consumer behavior research: A literature review and research agenda", Academy of Marketing Science Review, Vol. 10, pp. 1-31.

Park, C. W., Mothersbaugh, D. L. and Feick, L. (1994), "Consumer knowledge assessment", Journal of Consumer Research, Vol. 21, No. 1, pp. 71-82.

Quester, P. G. and Smart, J. (1998), "The influence of consumption situation and product involvement over consumers' use of product attribute", Journal of Consumer Marketing, Vol. 15, No. 3, pp. 220-238.

Raju, P. S., Lonial, S. C. and Mangold, W. G. (1995), "Differential effects of subjective knowledge, objective knowledge, and usage experience on decision making", Journal of Consumer Psychology, Vol. 4, No. 2, pp. 153-180.

Regan, D. T. (1971), "Effects of a favor and liking on compliance", Journal of Experimental Social Psychology, Vol. 7, pp. 627-639.

Spawton, A. L. (1991), "Grapes and wine seminar - prospering in the 1990s: Changing your view of the consumer", International Marketing Review, Vol. 8, No. 4, pp. 32-43.

Stryker, S. (1968), " Identity salience and role performance: The relevance of symbolic interaction theory for family research", Journal of Marriage and the Family, Vol. 4, pp. 558-564.

Vitz, P. C. and Johnston, D. (1965), "Masculinity of smokers and the masculinity of cigarette images", Journal of Applied Psychology, Vol. 49, pp. 155-159.

Whatley, M. A., Webster, J. M., Smith, R. H. and Rhodes, A. (1999), "The effect of a favor on public and private compliance: How internalized is the norm of reciprocity?" Basic and Applied Social Psychology, Vol. 21, No. 3, pp. 251-259.

Worth, L. T., Smith, J. and Mackie, D. M. (1992), "Gender schematicity and preference for gender-typed products", Psychology \& Marketing, Vol. 9, No. 1, pp. 17-30.

Zaichkowsky, J. L. (1985), "Measuring the involvement construct", Journal of Consumer Research, Vol. 12, No. 3, pp. 341-352. 